\title{
Effects of vibration in desert area caused by moving trains
}

\author{
Jabbar-Ali ZAKERI*, Morteza ESMAEILI, Seyedali MOSAYEBI, Rauf ABBASI \\ School of Railway Engineering, Iran University of Science and Technology, Tehran, Iran
}

\begin{abstract}
The ballast layer, filled with fine particles like blown sand, is one of the important problems of ballasted railway tracks in desert areas. Blown sand, as a contaminator of ballast layer, increases track stiffness and may cause serious damage to sleepers, pads, rails, and vehicles. In this paper, the effects of increasing track stiffness due to windy sands in the ballast layer and the train induced vibrations due to this phenomenon were studied. Based on field studies in a desert area in Iran, a two-dimensional finite/infinite element model for a railway track with plane strain condition was analyzed using the software ABAQUS, and the track vibrations were examined by changing the values of stiffness of ballast layer. Vibrations caused by the load of train at different distances from the cross-section of track were investigated, and the values of vertical vibration displacement, velocity, and acceleration were calculated. Results show that acceleration values of vertical vibration increase with the increasing of ballast layer stiffness caused by the filling of sand, while the vertical vibration velocity of track and the induced ground displacement decrease. The farther the distance from the source of vibration, the less the displacement, velocity, and acceleration. In addition, the methods for reducing train-induced vibrations were introduced.
\end{abstract}

Key words: train induced vibration; desert area; blown sand; ballast layer stiffness

(C) 2012 JMT. All rights reserved.

\section{Introduction}

$\mathrm{R}$ ailway lines have been designed and executed in most countries due to the expansion of suburban travels and induced traffic. However, the train traffic between cities creates vibrations in some areas especially where environmental conditions are severe, such as desert areas where the ballast layers are filled with blown sand. Produced vibrations can cause worrying effects on the existing structures and sensitive facilities in these areas because blown sand as contaminator of ballast layer cause the track stiffness to increase and therefore incur serious damage to sleepers, pads, rails, and vehicles. Indraratna and Salim [1] studied the mechanics of ballasted rail tracks. Selig and Waters [2] investigated track geotechnology and substructure management. Tutumluer and Dombrow [3] studied the effect of coal dust on railroad ballast strength and its stability. Also, Yang and Hung [4-5], Al-Hussaini and Ahmad [6], Adam and

This paper was presented at the 5th International Symposium on Environmental Vibration in Chengdu, China, October 2022, 2011, and recommended by the scientific committee of the symposium to JMT

Received Sep. 22, 2011; revision accepted Dec. 7, 2011

*Corresponding author. Tel.: +98-21-77491029-30, IUST ex-

tension 3517; Fax: +98-21-77451568/73228517

E-mail: zakeri@iust.ac.ir (J.A. ZAKERI)

(C) 2012 JMT. All rights reserved

doi: 10.3969/j.issn.2095-087X.2012.01.003
Estorff [7], and Graff [8] worked in field of wave propagation for train-induced vibrations. However, modeling of subgrade and estimation of dynamic vibration with respect to the effects of blown sand have not been considered in most studies [9-10]. Therefore, in this study, fields studies were conducted in desert areas of Iran rich of blown sand, and the effects of train induced vibrations in these areas with different ballast layer stiffness were investigated using the software ABAQUS.

\section{Stiffness and settlement of railway track}

Fig. 1 shows different components of a rail track. Many factors such as particle shape, aggregate size distribution, moisture, etc., affect the stiffness of ballast. For example, sheet-shape particles increase wear rate, breakage, and cumulative permanent strain; and they reduce the track stiffness. Therefore, most researchers recommend cubic shape for ballast particle in the railway tracks. On the other hand, dry ballast has lower hardness than the wet ballast. The reduction in effective stresses between particles, cause the strength, hardness, and eventually resilient modulus to reduce. When trains pass on a track and different loads induced by the train with different frequencies are applied to the structure of track, the ballast and subgrade may undergo non-elastic deformations [11-12]. After the train passes, the track 
does not return to its original position and a small deformation occurs in the path. With thousands of trains passing on the track, the cumulative effect of these small non-elastic deformations creates a new track position. This phenomenon is called differential track settlement. If the settlement of track occurs uniformly throughout the path, no problem will happen [13]. More than 50\% of settlement in path (either uniform or variable) is due to the ballast layer. Causes of permanent deformations in railways are (a) reduction of volume or densification of ballast layer due to particle rearrangement induced by repeated train loads, (b) inelastic recovery of ballast layer for stress removal or unloading, (c) volume reduction of ballast layer due to particles breakage from environmental factors or train loading, and (d) subgrade penetration into ballast layer voids. The first two causes (a and b) apply to both ballast and subgrade, the third cause (c) mainly to ballast, and the fourth cause (d) to subgrade [1-2, 14-16].

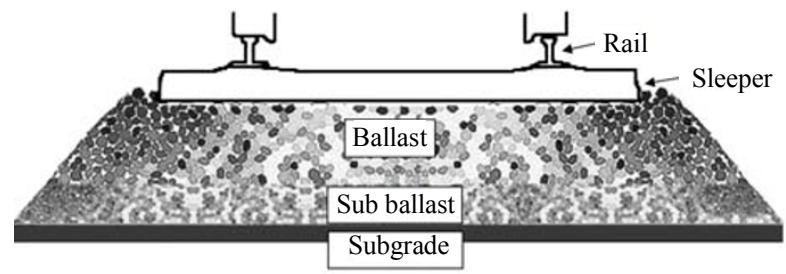

Fig. 1 Components of conventional railway track

\section{Contamination of superstructure in track}

Contamination sources of ballast layer fall into five categories [2]:

- abrasion effect of sleeper,

- penetration from upper surface of ballast,

- penetration through pavement path,

- penetration of fine particle in beneath layers, and

- rupture of ballast.

Crucial phases of particle deposits are classified into three categories:

(1) Clean ballast: almost all aggregates are presumed to establish contact with each other at the surface of aggregates to bear the load (Fig. 2(a)).

(2) Partially fouled or dirty ballast: voids exist in between aggregates filled with fine particles, but contacts of aggregates are still maintained (Fig. 2(b)).

(3) Fouled ballast: due to an extreme amount of fine particles, contacts between aggregates are mostly removed, and the aggregate particle movements are then only constrained by the fine particles filling the voids between the particles (Fig. 2(c)) [9].

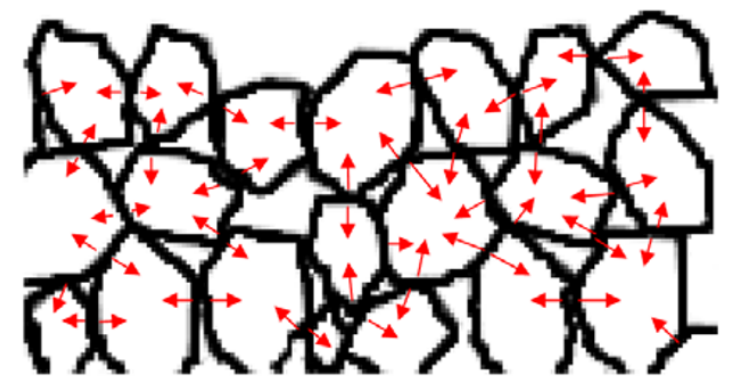

(a) Clean ballast

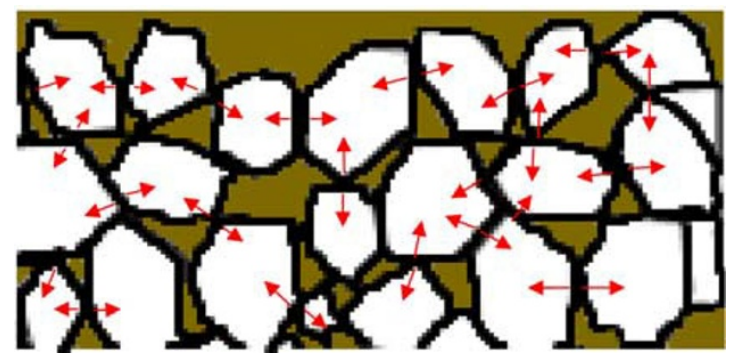

(b) Dirty ballast

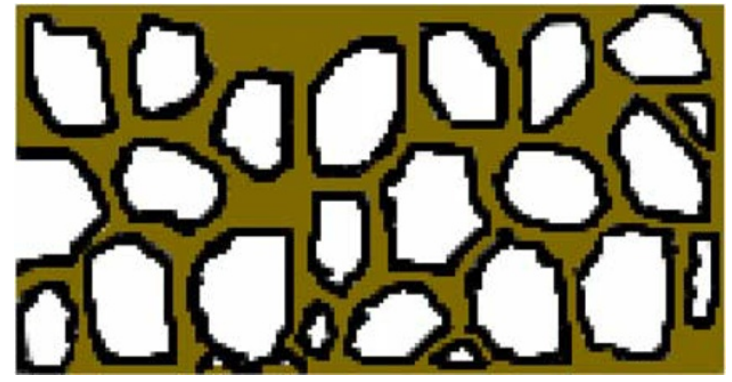

(c) Fouled ballast

Fig. 2 Ballast fouling stages

When ballast samples are fouled, the shear resistance reduces. Fig. 3 shows samples of fouled ballast by blown sand in Iran.

\section{Field experiment}

In this work, Bafgh-Mashhad railway route in the east district of Iranian railways, used for freight transit, were investigated. Because of the existing wind erosion and sand dunes during the train operation, some blocks of the route had a severe condition. In this railway route,

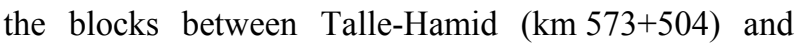
Montazer Ghaem (km 558+294) stations were investigated. Five different sites (Fig. 4) for field test were selected according to the presence of sands flowing between the grains of ballast layer: the fouling percentage of ballast layer ranged from $12 \%$ to $60 \%$ for track modules of $50 \mathrm{MPa}$ to $110 \mathrm{MPa}$. The ballast materials were sampled from each of the sites for aggregate gradation test in laboratory. 


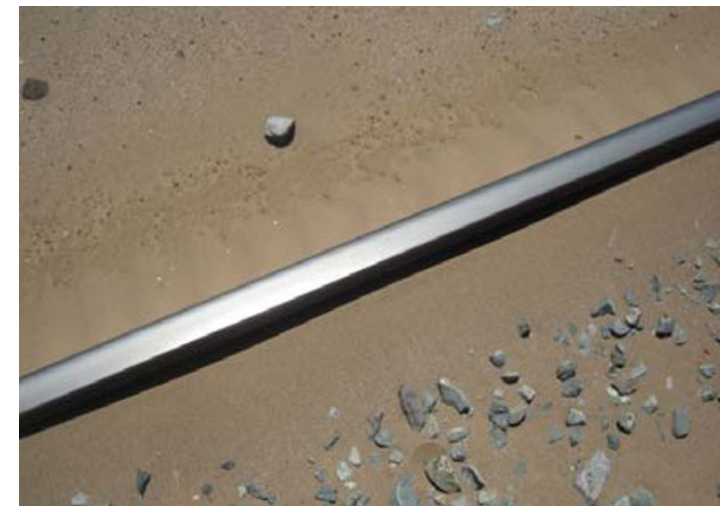

(a)

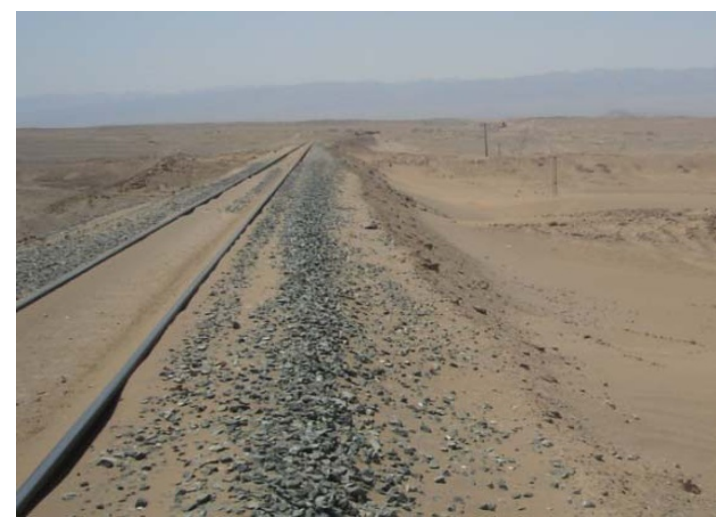

(b)

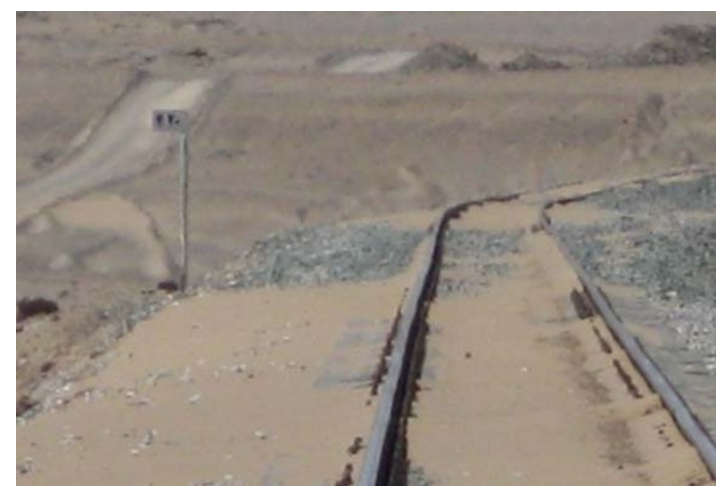

(c)

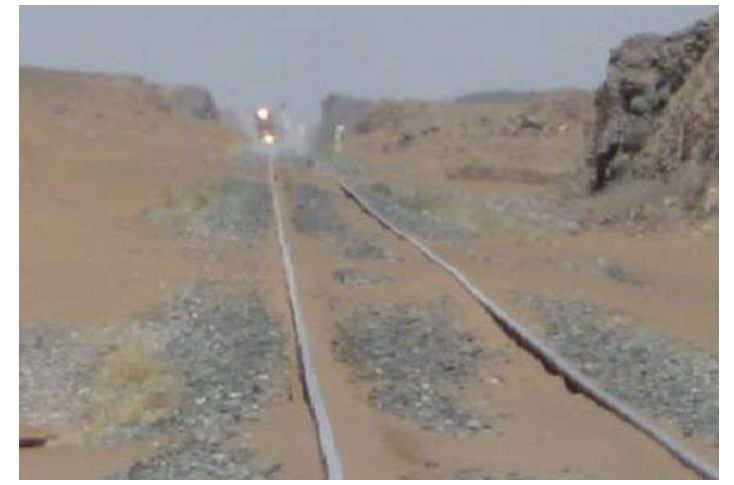

(d)

Fig. 3 Fouled ballast layer by blown sand in desert area

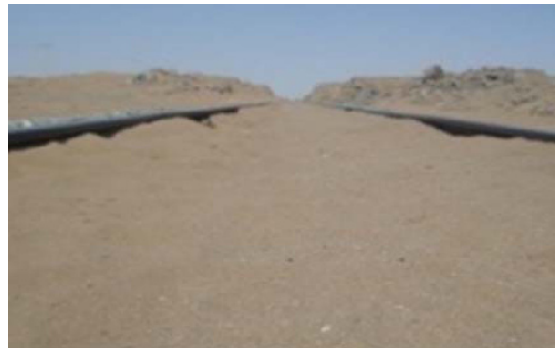

(a) Site 1 (fouling percentage $60 \%$ )

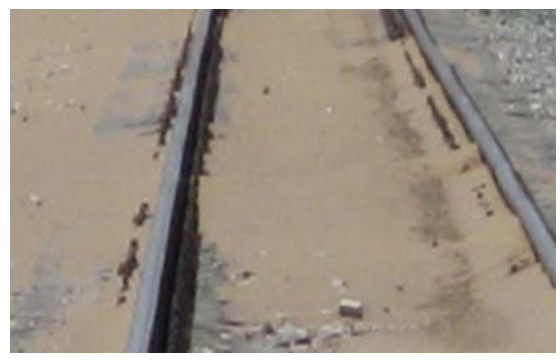

(b) Site 2 (fouling percentage $52.6 \%$ )

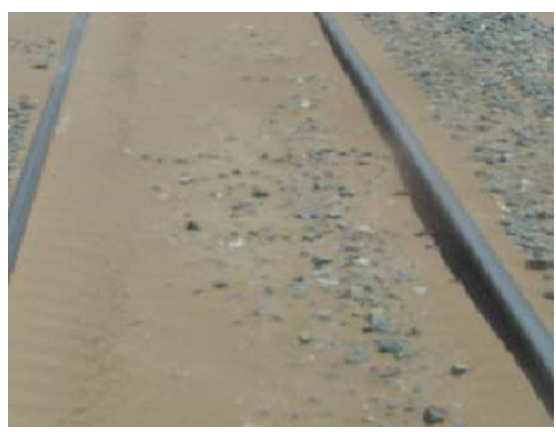

(c) Site 3 (fouling percentage $27.5 \%$ )

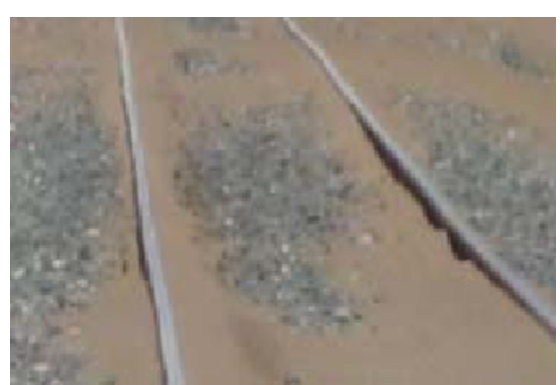

(d) Site 4 (fouling percentage 18.9\%)

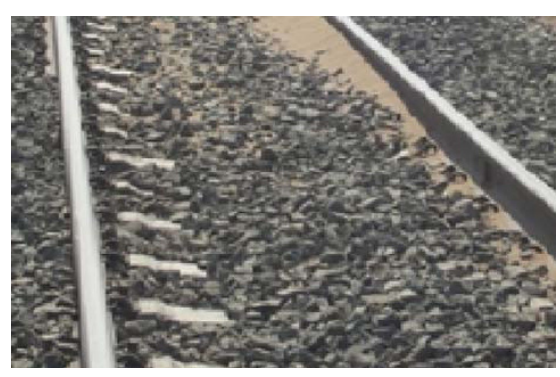

(e) Site 5 (fouling percentage 12\%)

Fig. 4 Selected sites based on the rate of ballast fouled for field tests 
Talbot-Wasiutynski method [17-18] was used for the calculation of rail bed modulus. In this method, both heavy and light loads are used to generate vertical settlements of track, and then the modulus values of bed are estimated. In order to measure the vertical settlement of track caused by the load from vehicle wheels, five sensors of linear variable differential transformer (LVDT) were installed in adjacent sleepers. By testing the displacements of sleepers at every site, values of rail bed modulus were calculated by Talbot-Wasiutynski method. Table 1 represents the results of measurements and calculations for the modulus of the rail bed.

Table 1 Test results of rail bed modulus at different sites

\begin{tabular}{cccc}
\hline Test site & $\begin{array}{c}\text { Heavy wheel } \\
\text { load }(\mathrm{kN})\end{array}$ & $\begin{array}{c}\text { Light wheel } \\
\text { load }(\mathrm{kN})\end{array}$ & $\begin{array}{c}\text { Rail bed } \\
\text { modulus }(\mathrm{MPa})\end{array}$ \\
\hline Site 1 & 93 & 10 & 110 \\
Site 2 & 93 & 10 & 95 \\
Site 3 & 93 & 10 & 80 \\
Site 4 & 93 & 10 & 65 \\
Site 5 & 93 & 10 & 50 \\
\hline
\end{tabular}

\section{Numerical results of train induced vibra- tions}

By using ABAQUS software, a two-dimensional railway track with plane strain conditions was analyzed, and track vibrations were examined by changing the values of ballast layer stiffness. The results are compared with the test results shown in Table 1. Firstly the field experiment with static analysis was verified, and then dynamic load of railway was applied until the vibrations caused by axle load at the different distances from the cross-section of track were achieved. The amounts of vertical vibration displacement, velocity and acceleration were examined. In this analysis, the load of railway was considered as the step load [19] indicated in Fig. 5.

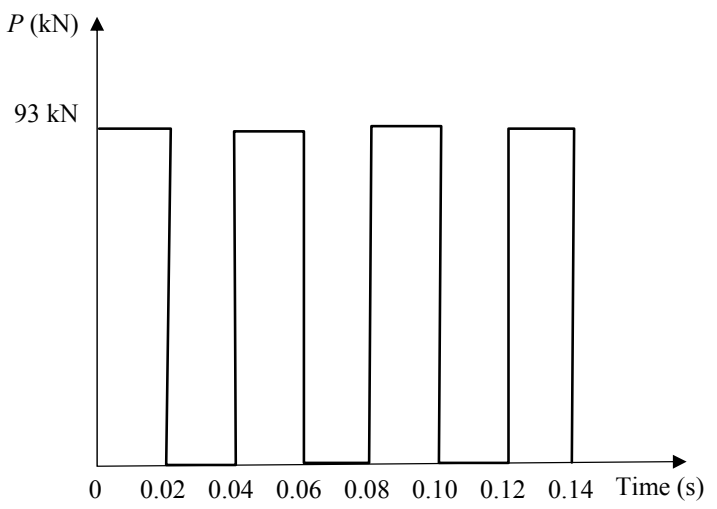

Fig. 5 Step load of train
Then, finite and infinite elements were used in the modeling of track and its bed (infinite elements in boundary) [20]; see Fig. 6. To further assess the ground vibration caused by the passing train at each site with different ballast fouling percentage, the ground displacements in four sections with different distances from the end point of the ballast shoulder were calculated by the established model: one section just under the train wheel load, and others at 2, 5, and $10 \mathrm{~m}$ from end of ballast shoulder.

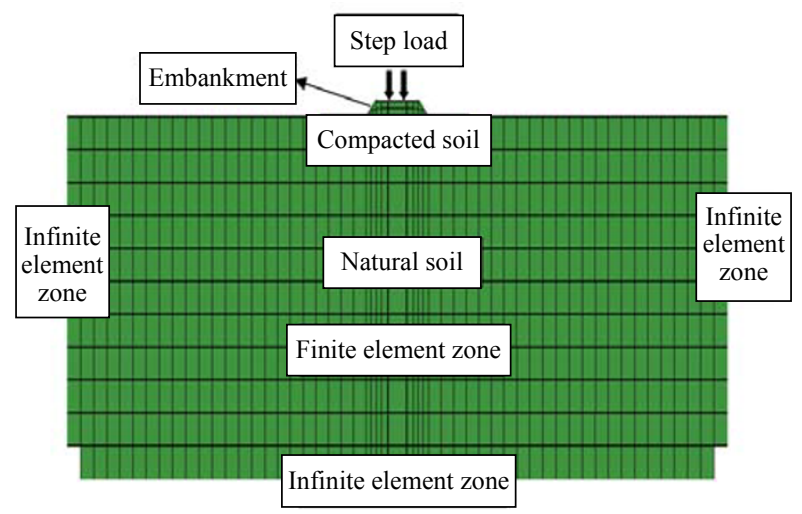

Fig. 6 Modeling of track and bed with finite/infinite elements

The results examined from vibration of track with respect to applied load and field experiment for five sites, are calculated. Figs. 7, 8, and 9 show vertical vibration displacement, velocity and accelerations respectively for the five sites. The rail bed modulus for ballasted railway track changes from $110 \mathrm{MPa}$ at site 1 with maximum fouling percent of ballast $(60 \%)$ to $50 \mathrm{MPa}$ at site 5 with $12 \%$ of ballast contamination in central desert of Iran. One can see from these figures that as rail bed modulus or stiffness increases from 50 to $110 \mathrm{MPa}$, the acceleration of track vertical vibration increases about $25.4 \%$ under axle load, while the vertical vibration velocity decreases about $6.1 \%$ and $32 \%$. Moreover, the displacement of track decreases about $46.2 \%$ and $31.2 \%$, under the axle load and at $2 \mathrm{~m}$ from ballast shoulder, respectively. Thus, at a particular point from end point of ballast shoulder, absolute amplitude ground displacement and velocity usually decrease with increasing ballast contamination percentage. These values at that particular point under train load have more intensity than other points. Nevertheless, the farther the distance from the source of vibration, the less displacement, velocity, and acceleration. For example, when the distance from the vibration source increases to $5 \mathrm{~m}$, the vertical displacements of track decrease about $79 \%, 78.12 \%, 79.45 \%, 82.35 \%$, and $91 \%$ for site 1 to site 5 , respectively. Similarly, the ground velocity at 2,5 , and $10 \mathrm{~m}$ from end point of ballast shoulder of site 1 decreases about $75.4 \%, 77.6 \%$, and $88.36 \%$, respectively, compared to that under track. 


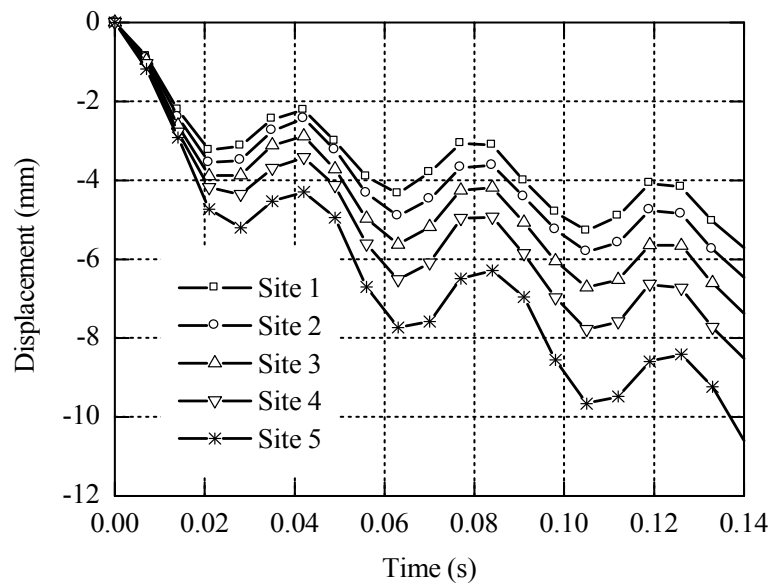

(a) Displacement under track

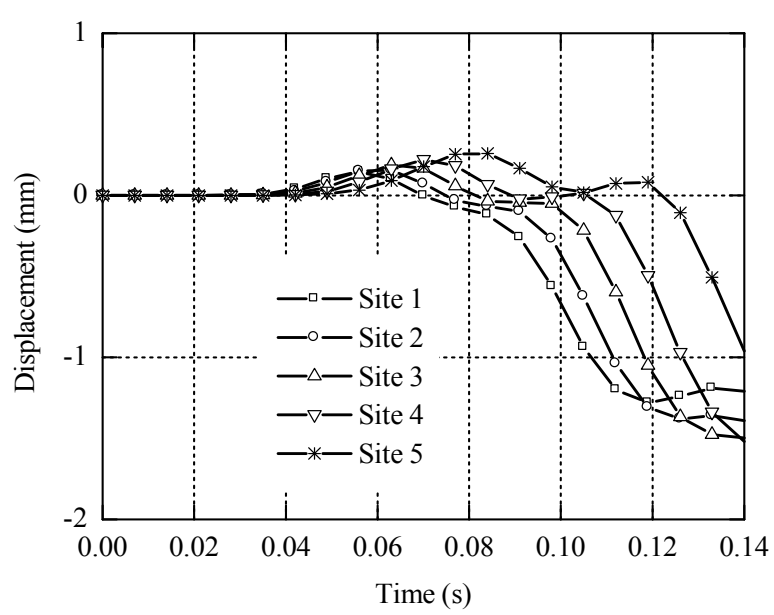

(c) Displacement at $5 \mathrm{~m}$ from end point of ballast shoulder

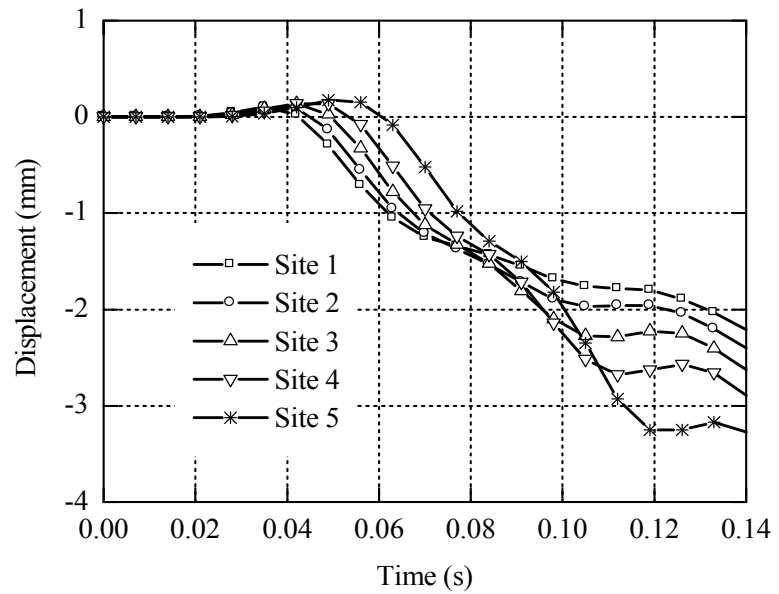

(b) Displacement at $2 \mathrm{~m}$ from end point of ballast shoulder

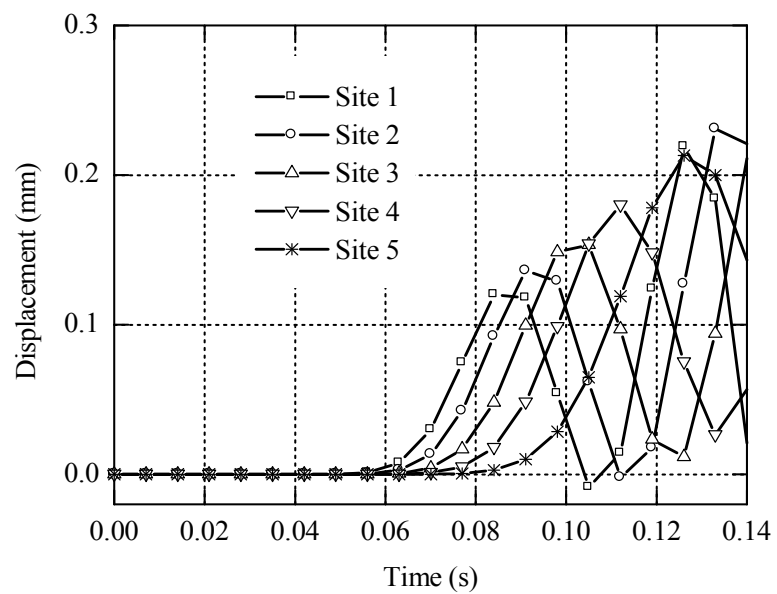

(d) Displacement at $10 \mathrm{~m}$ from end point of ballast shoulder

Fig. 7 Comparison of vertical vibration displacement for five sites

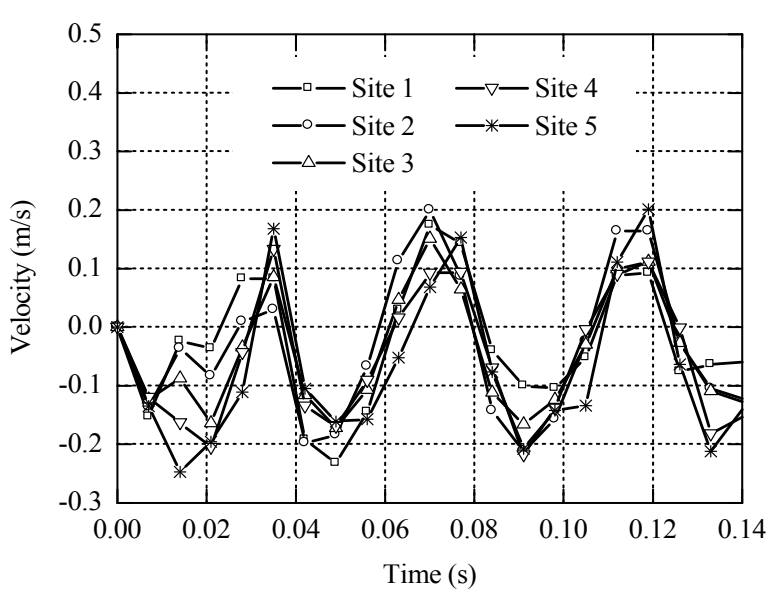

(a) Velocity under track

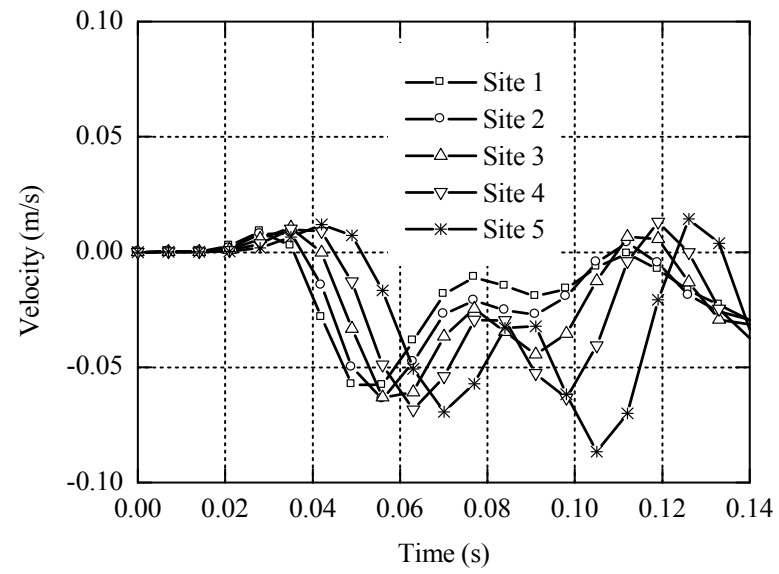

(b) Velocity at $2 \mathrm{~m}$ from end point of ballast shoulder 


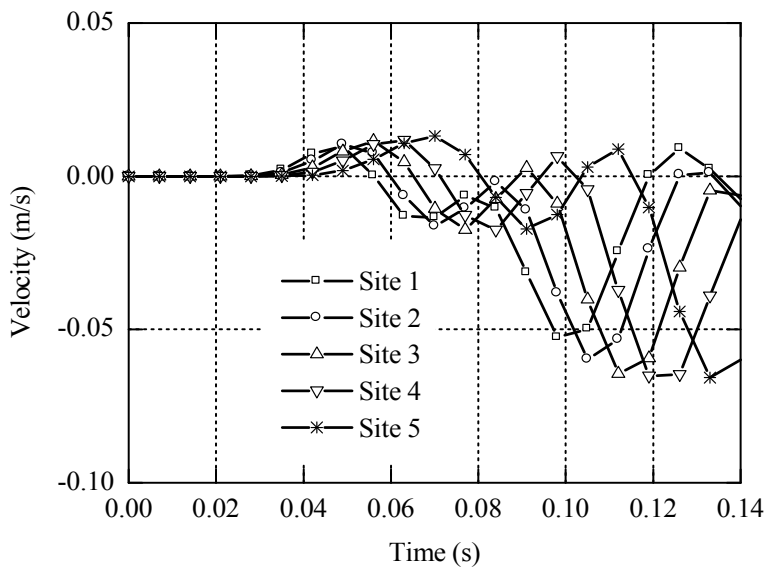

(c) Velocity at $5 \mathrm{~m}$ from end point of ballast shoulder

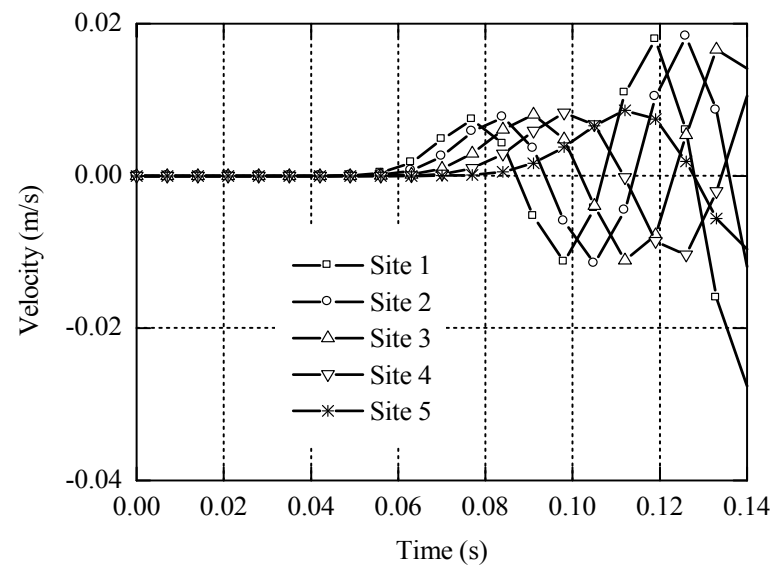

(d) Velocity at $10 \mathrm{~m}$ from end point of ballast shoulder

Fig. 8 Comparison of vertical vibration velocity for five sites

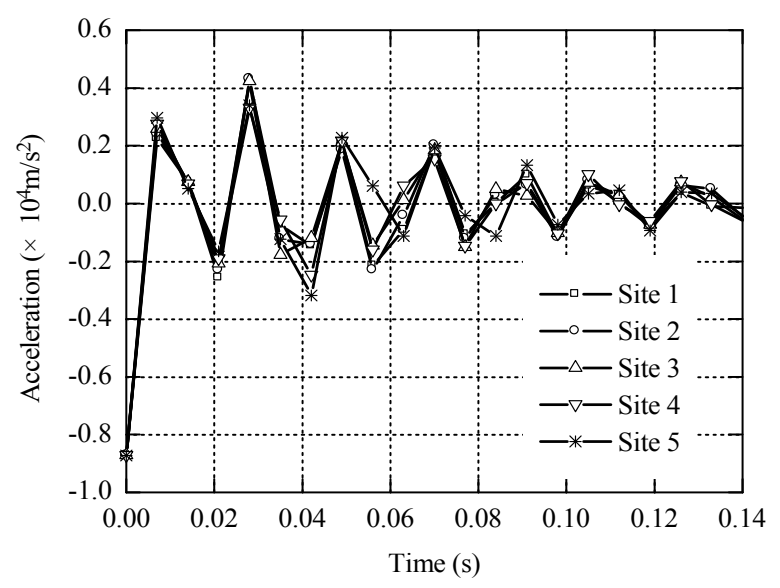

(a) Acceleration under track

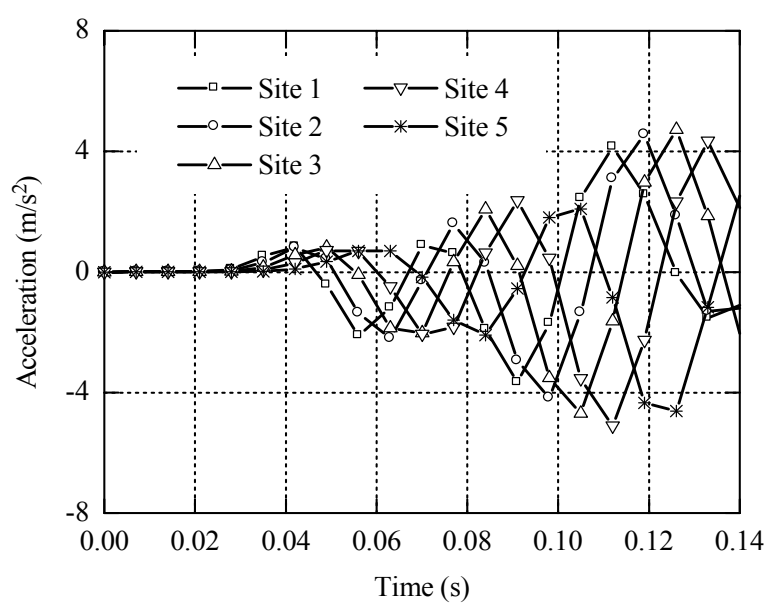

(c) Acceleration at $5 \mathrm{~m}$ from end point of ballast shoulder

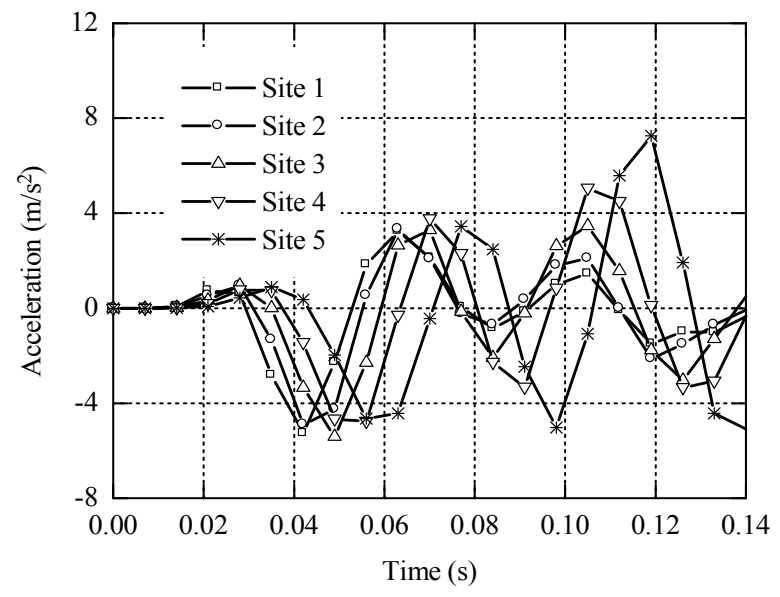

(b) Acceleration at $2 \mathrm{~m}$ from end point of ballast shoulder

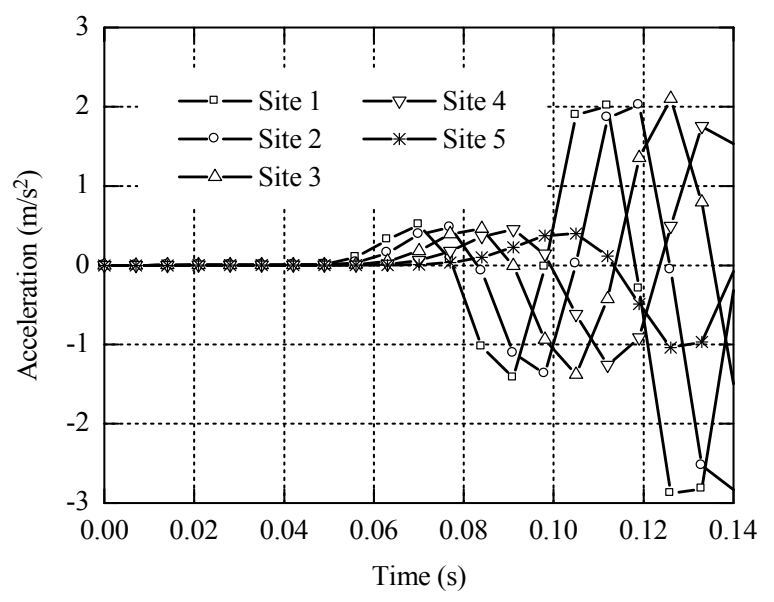

(d) Acceleration at $10 \mathrm{~m}$ from end point of ballast shoulder

Fig. 9 Comparison of vertical vibration acceleration for five sites 
Table 2 Amplitude of maximum ground displacement

\begin{tabular}{cccccc}
\hline \multirow{2}{*}{ Position } & \multicolumn{5}{c}{ Maximum ground displacement (mm) } \\
\cline { 2 - 5 } & Site 1 & Site 2 & Site 3 & Site 4 & Site 5 \\
\hline Under track & -5.7 & -6.4 & -7.3 & -8.5 & -1.06 \\
At 2 $\mathrm{m}$ from end point of ballast shoulder & -2.2 & -2.3 & -2.6 & -2.8 & -3.2 \\
At 5 m from end point of ballast shoulder & -1.2 & -1.4 & -1.5 & -1.5 & -0.96 \\
At 10 $\mathrm{m}$ from end point of ballast shoulder & 0.21 & 0.23 & 0.21 & 0.17 & 0.21 \\
\hline
\end{tabular}

Table 2 shows the amplitudes of maximum ground displacements induced by track vibration for different sites. One can see that as the modulus or stiffness of track increases from 50 to $110 \mathrm{MPa}$, the maximum ground displacement decreases about $46.2 \%$ and $31.2 \%$ under track and at $2 \mathrm{~m}$ from ballast shoulder, respectively.

\section{Methods for reducing train induced vi- brations}

The methods for reducing the train induced vibrations can be classified into the following three categories [21]:

(a) Vibration reduction in source, for example, using resilient direct fixation fasteners, precision rails, alignment modification, rail grinding, wheel truing, welded rail, resilient wheels, stabilization of soil under the embankment, reduction of train speed, floating slabs, and low stiffness vehicle suspension systems.

(b) Vibration reduction in the path of propagation, for example, constructing impediment, trenches, and walls.

(c) Vibration reduction in receiver (buildings), for example, using elastic foundation and increasing distance between source and receiver.

\section{Conclusion}

Blown sand, as a polluter of the ballast layer in railway lines, increases the track stiffness, and therefore will incur serious damage to sleepers, pads, rails, and vehicles. In this paper, field experiments were made to measure the effects of blown sand on rail bed modulus in the desert area of Iran. Using software ABAQUS, a two-dimensional finite/infinite element model with plane strain condition for railway track was analyzed, and the vertical displacement, velocity, and accelerations of track vibrations were examined by changing the values of ballast layer stiffness. The results show that as the rail bed modulus or stiffness increases, the acceleration of track vertical vibration increases, but the vertical vibration velocity of track and the induced ground displacement decreases. The farther the distance from the source of vibration, the less the displacement, velocity, and acceleration.

\section{References}

[1] B. Indraratna, W. Salim, Mechanics of Ballasted Rail Tracks: A Geotechnical Perspective, London: Taylor \& Francis/Balkema, 2005.

[2] E.T. Selig, J.M. Waters, Track Geotechnology and Substructure Management, London: Thomas Telford, 1994.

[3] E. Tutumluer, W. Dombrow, H. Huang, Effect of coal dust on railroad ballast strength and stability, In: 8th International Conference on Bearing Capacity of Roads, railways and Airfields, The University of Illinois at Urbana-Champaign, June 29-July 2, 2009, Champaign, Illinois, USA.

[4] Y.B. Yang, H.H. Hung, Wave Propagation for TrainInduced Vibrations: A Finite/Infinite Element Approach, Singapore: World Scientific Publishing Co. Pte. Ltd., 2008.

[5] Y.B. Yang, H.H. Hung, A parametric study of wave barriers for reduction of train-induced vibrations, Int. J. Num. Meth. Eng., 1997, 40: 3729-3747.

[6] T.M. Al-Hussaini, S. Ahmad, Design of wave barriers for reduction of horizontal ground vibration, Journal of Geotechnical and Geoenvironmental Engineering, 1991, 117(4): 616-636.

[7] M. Adam, O. Estorff, Reduction of train-induced building vibrations by using open and filled trenches, Computers and Structures, 2005, 83: 11-24.

[8] K.F. Graff, Wave Motion in Elastic Solids, New York: Dover Publications, Inc., 1973.

[9] A. Karlström, A. Boström, Efficiency of trenches along railways for trains moving at sub- or supersonic speeds, Soil Dynamics and Earthquake Engineering, 2007, 27(7): 625-641.

[10] Y.B. Yang, Y.B. Hung, A 2.5D finite/infinite element approach for modeling visco-elastic bodies subjected to moving loads, Int. J. Num. Meth. Eng., 2001, 51(11): 1317-1336.

[11] J.A. Zakeri, H. Xia, J.J. Fan, Dynamic responses of train-track system to single rail irregularity, Latin merican Journal of Solids and Structures, 2009, 6(2): 89-104. 
[12] B. Aursudkij, A Laboratory Study of Railway Ballast Behaviour under Traffic Loading and Tamping Mainteance [Dissertation], Nottingham: The University of Nottingham, 2007.

[13] J.A. Zakeri, R. Abbasi, Field investigation on distribution of contact pressure between sleeper and saturated ballast with flowing sand, In: 11th International Conference on Railway Engineering, London, UK, 2011.

[14] T. Dahlberg, Railway track settlements: report for the EU project supertrack, Linköping, Sweden: Linköping University, 2002.

[15] A. Suiker, Fatigue behavior of granular materials, Part 1constitutive modeling and description of experiments, Tu-Delft Report No.7-97-119-2, Delft University of Technology, Netherlands, 1997.

[16] D. Ionescu, B. Indraratna, H.D. Christie, Behavior of railway ballast under dynamic loads, In: Thirteenth Southeast Asian Geotechnical Conference, Taiwan, 1998.

[17] A.N. Talbot, ASCE-AREA committee on stresses in rail road tracks, first progress report, In: Proceedings of AREA, Vol. 19, 1918.

[18] A. Wasiutynski, Experimental research on the elastic deformations and stresses in a railroad track, In: Annales de L'Academie des Sciences Techniques á Varsavie, Vol.5, Dunod, Paris, France, 1937 (in French).

[19] G. Di Mino, M. Giunta, C. Di Liberto, Assessing the open trenches in screening railway ground-borne vibrations by means of artificial neural network, Advances in Acoustics and Vibration, Vol. 2009, Article ID 942787, 2009.

[20] J.A. Zakeri, H. Xia, Application of 2D-infinite beam elements in dynamic analysis of railway track, Journal of Mechanical Science and Technology, 2009, 23(5): 1415-1421.

[21] M. Bahrekazemi, Train-induced ground vibration and its prediction [Dissertation], Stockholm: Royal Institute of Technology KTH, 2004.

(Editor: Junsi LAN)

\section{Congratulations to Prof. Wanming Zhai, associate Editor-in-Chief of JMT, elected as an academician of Chinese Academy of Sciences}

$\mathrm{C}$ ongratuations to Wanming Zhai, Ph.D., associate Editor-in-Chief of Journal of Modern Transportation (JMT), who was among the 51 newly elected academicians announced by Chinese Academy of Sciences (CAS) on Dec. 9, 2011. Dr. Zhai is a professor at Southwest Jiaotong University, deputy director of Traction Power State Key Laboratory, and director of Key Laboratory of High-Speed Railway Engineering.

Dr. Zhai has made a significant amount of contributions in the field of railway vehicle dynamics. He put forward a unified vehicle-track interaction model, which was regarded as one of four most representative models by the academic community in railway engineering; and established a theoretical framework of vehicle-track coupling dynamics, which was believed to be a major breakthrough in modeling the wheel-rail coupled dynamics and simulating the vibration of crushed stone ballast.

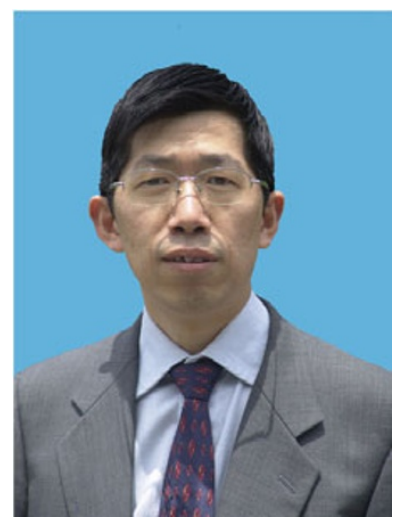
These achievements have been granted with First-Class National S\&T Progress Award in 2005. Moreover, Dr. Zhai stipulated the guidelines for optimal design of matching between vehicles and tracks, which was validated by the Speed-Raising Projects of China's Railways and the Priority Projects of China's Passenger Dedicated Lines. Based on Newmark implicit integration method, Dr. Zhai developed an explicit numerical integration algorithm to rapidly and efficiently solve problems of the grand, complicated, non-linear coupled vehicletrack system. Dr. Zhai has published 2 books and over 160 papers in the prestigious journals. He has received various rewards for his outstanding performances, such as Young Scientist Award of China, Cheung Kong Scholars Achievement Award and Ho Leung Ho Lee Award. 